\title{
AS ALTERAÇÕES NA DESCONSIDERAÇÃO DA PERSONALIDADE JURÍDICA PELA LEI DA LIBERDADE ECONÔMICA E SEUS REFLEXOS NOS RAMOS DO DIREITO
}

\author{
THE AMENDMENTS IN THE DISREGARD DOCTRINE BY ECONOMICAL \\ FREEDOM ACTAND ITS REFLECTIONS IN THE LAW FIELDS
}

\author{
José Antônio Ribeiro de Oliveira Silva ${ }^{1}$ \\ Bruno Luís Costa Silva ${ }^{2}$ \\ Daniela Monteiro Trevizani ${ }^{3}$
}

Aceito em 03/04/2021

\section{RESUMO}

A personalidade jurídica configura um ente autônomo, com direitos/obrigações distintas da pessoa de seus constituintes. Contudo, esse instituto pode ser utilizado para fins ilícitos. Assim, existindo abuso da personalidade jurídica, desconsidera-se a autonomia patrimonial no caso em concreto para se estender as obrigações aos integrantes da empresa. Em meio a isto, surge Lei n. 13.874/19 (Lei da Liberdade Econômica), modificando os aspectos da desconsideração da personalidade jurídica presentes no artigo 50 do Código Civil. Devido à urgência dessa Lei pelo alto desemprego no Brasil, imperioso a análise jurídica dos seus efeitos. Assim, os estudos focaram nas peculiaridades da desconsideração da personalidade jurídica, passando-se para os efeitos do novo artigo 50 nos diversos campos jurídicos. Com uma análise doutrinária, legal e jurisprudencial, constatou-se que a Lei da Liberdade Econômica modificou a teoria maior da desconsideração, aplicando-se diretamente nas relações comerciais e tributárias. Todavia, devido à hipossuficiência presente nas legislações trabalhista e consumerista, concluiuse que a desconsideração nesses campos permanece conforme a teoria menor. Ademais, mesmo em se aplicando as modificações, aconselha-se que a jurisprudência apresente situações excepcionais de condutas que presumam o dolo, bem como se inverta o ônus probatório para o empresário em se preenchendo os requisitos do art. 373 do CPC.

Palavras-chave: Desconsideração da personalidade jurídica. Lei da Liberdade Econômica. Teoria maior e menor da desconsideração da personalidade jurídica. Incidente de desconsideração da personalidade jurídica.

\section{ABSTRACT}

The legal personality configures an autonomo usentity, with rights/obligations distinct from the person of its constituents. However, it maybe used for unlawful purposes. Thus, if there is abuse of legal personality, the autonomy of assets is disregarded in the specific case to extend

\footnotetext{
${ }^{1}$ Juiz do Trabalho Titular da $6^{\text {a }}$ Vara do Trabalho de Ribeirão Preto (SP), do TRT da $15^{\text {a }}$ Região; Membro do Conselho Técnico da Revista do TRT $15^{\mathrm{a}}$ Região; Mestre em Direito Obrigacional Público e Privado pela UNESP/SP; Doutor em Direito do Trabalho e da Seguridade Social pela UCLM - Universidad Castilla-la Mancha (ESPANHA), título revalidado pela Universidade de São Paulo (USP); Professor da Escola Judicial do TRT da $15^{\mathrm{a}}$ Região; Professor Contratado do Departamento de Direito Privado da USP de Ribeirão Preto (SP).

${ }^{2}$ Possui formação em Direito pela Faculdade de Direito de Franca-SP (2017); é advogado com aprovação no XXIII Exame da Ordem dos Advogados do Brasil e Especialista em Compliance pela FGV; aprovado no concurso para Professor Substituto de Direito Administrativo na Faculdade de Direito de Franca-SP (2019), instituição que também exerceu as atividades de monitor de Direito Administrativo.

${ }^{3}$ Possui formação em Direito pela Faculdade de Direito de Franca-SP (2018); é advogada com aprovação no XXVI Exame da Ordem dos Advogados do Brasil; é advogada da Unimed Nordeste Paulista.
} 
the obligations to the members of the company. In the midst of this, Economical Freedom Act (n. 13.874/19) appears, modifying the aspects of the disregard doctrine present in article 50 of the Civil Code. Due the urgency of this act because of the high unemployment in Brazil, it is imperative to analyze the legal effects. Thus, the studies focused on the peculiarities of disregarding doctrine, moving to the effects of the new article 50 in the various legal fields. With a doctrinal, legal and jurisprudential analysis, it was verified that the Economical Freedom Act modified the major theory of disregard, applying directly in the commercial and tax relationships. However, due to the hyposufficiency present in labor and consumer legislation, it was concluded that disregard in the sefields remains according to the minor theory. In addition, even in applying these modifications, it is advised that the jurisprudence presents exceptional situations of conducts that presume malice, as well as reversing the evidentiary burden for the entrepreneur in fulfilling the requirements of CPC's article 373.

Keywords: Disregard doctrine. Economical Freedom Act. Major and Minor disregard doctrine. Incident of disregard doctrine.

\section{INTRODUÇÃO}

A personalidade jurídica possui importância múltipla. De um lado, incentiva o desenvolvimento de atividades econômicas produtivas, aumenta a arrecadação de tributos, produz empregos e incrementa o desenvolvimento econômico-social da sociedade. Do outro, cria-se um instituto em prol daqueles que exercem as atividades econômicas de forma que os riscos inerentes à atividade sejam limitados.

Deste modo, a personalidade jurídica configura um ente repleto de autonomia, com direitos e obrigações que não se confundem com a pessoa de seus constituintes, os quais apenas investem parte do seu patrimônio, assumindo riscos limitados de prejuízo. Isto ocorre para que não se reduza o potencial de investimentos, de modo que se estimule o exercício da atividade econômica, essencial para criação de empregos e capital.

Contudo, ainda que a autonomia patrimonial da pessoa jurídica seja de suma importância para o estímulo de investimentos e do empreendedorismo, o mesmo instituto pode ser utilizado para fins ilícitos, como a facilitação da corrupção e lavagem de dinheiro. Ciente deste fator, as disposições acerca do regime patrimonial das pessoas jurídicas devem conciliar dois objetivos conflitantes: incentivar investimentos em atividades produtivas com o mínimo de fraudes e prejuízos ilícitos a terceiros.

Para tanto, em situações de abuso da personalidade jurídica, nada mais justo do que retirar os privilégios normativos, descartando-se a autonomia patrimonial no caso em concreto para se estender as obrigações aos constituintes da empresa. Tal instituto, consistente em um "descarte eventual" da personalidade jurídica, recebe o nome de desconsideração (diferindo do termo despersonalizar, que seria a extinção da personalidade).

A desconsideração da personalidade jurídica, portanto, representa importante instituto para se assegurar tanto os interesses da sociedade, como os da própria empresa e dos demais sócios. Além disso, pune os desvios éticos daqueles que são incapazes de agir conforme as prerrogativas legais.

Em meio a este cenário, surge a Lei n. 13.874/19, a "Lei da Liberdade Econômica". Seus anseios remetem à valorização da iniciativa privada e dos direitos individuais assegurados pelo liberalismo. Fornecendo algumas inovações no instituto da desconsideração da personalidade jurídica ao alterar o artigo 50 do Código Civil, a Lei n. 13.874/19 recebeu diversas críticas e elogios. 


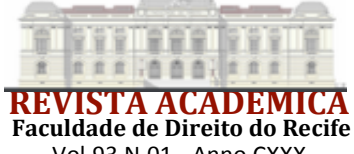

Vol.93 N.01 - Anno CXXX

Tendo em vista a urgência da Lei da Liberdade Econômica devido aos altos índices de desemprego que assolam o país, imperioso será a análise jurídica dos efeitos dessa nova lei. Assim, um estudo sobre as peculiaridades e situações legais da desconsideração da personalidade jurídica serão ponto de partida essencial do presente artigo, passando-se para a menção das alterações no artigo 50 do Código Civil e seus efeitos nos diversos campos jurídicos.

\section{DISPOSIÇÕES PRELIMINARES ACERCA DA DESCONSIDERAÇÃO DA PERSONALIDADE JURÍDICA}

A doutrina da desconsideração da personalidade jurídica surgiu na jurisprudência inglesa em 1897, no caso Salomon vs. Salomon \& Co. O comerciante Aaron Salomon constituiu uma companhia ("company"), para quem cedeu seu fundo de comércio. Salomon recebeu, em contrapartida, vinte mil ações representativas do capital social desta sociedade, enquanto os outros seis sócios, todos seus familiares, receberam uma ação cada, para integrarem o capital social daquela companhia. Diante desta transação, Aaron Salomon recebeu obrigações garantidas no valor de dez mil libras esterlinas. Por conta do fato ocorrido, a sociedade logo se tornou insolvente, não tendo recursos para satisfazer seus débitos perante terceiros (ASSIS, 2008).

Ingressando em juízo, o liquidante sustentou a tese de que a atividade da companhia nada mais era que a atividade de Salomon, sendo que este desejava limitar sua responsabilidade e que na verdade era ele quem deveria arcar com as dívidas. Em primeira instância, acolheu-se a desconsideração da personalidade jurídica para atingir a pessoa de Aaron Salomon. Todavia, em segundo grau, a sentença foi reformada. Mesmo assim, surgiu o precedente necessário para que um estudo mais elaborado acerca deste instituto fosse proposto.

Ressalte-se que os Tribunais norte-americanos vinham aplicando a disregardof legal entity ("desconsideração da entidade legal") apenas em casos excepcionais, onde se comprovasse fraude à lei, ao contrato ou a credores. Houve, contudo, uma ampliação desse entendimento, justificando-se a aplicação da teoria da desconsideração sempre que as circunstancias do caso concreto e a aplicação das normas vigentes levasse a resultados injustos (FONSECA, 1996).

No que tange à França, entende-se que pessoa jurídica é considerada com base em determinados fins, os quais são responsáveis, também, pela limitação do seu campo de abrangência. De acordo com a esquematização proposta por Erlinghagen, a desconsideração da pessoa jurídica aplicar-se-ia nas situações onde ocorressem simulação, aparência e interposição de pessoas. Merece destaque, também, a contribuição de Josserand, que a partir da jurisprudência dos Tribunais franceses sistematizou a teoria do abuso de direito, enfatizando que todo ato que fosse contrário a essa finalidade, ainda que com respaldo da lei, seria abusivo e, por conseguinte, atentatório ao Direito (FONSECA, 1996).

Também de relevante importância foi a influência alemã para a consolidação do instituto da desconsideração. Os estudos pioneiros do Prof. Rolf Serick propiciaram larga difusão da teoria da desconsideração da personalidade jurídica na Alemanha, chegando-se, inclusive, à elaboração de uma teoria semelhante designada de Durchgriff. Semelhante aos outros países, poder-se-ia desestimar a personalidade jurídica quando a mesma era utilizada abusivamente para fins ilícitos, bem como nos casos de infração a obrigações contratuais e de prejuízos fraudulentos a terceiros (FONSECA, 1996).

No Brasil, o tema foi abordado inicialmente pelo Prof. Rubens Requião, em conferência intitulada "Abuso de direito e fraude através da personalidade jurídica", realizada na Universidade Federal do Paraná (FONSECA, 1996). A semente dessas indagações foram 
justamente as evidências de que não era raro a utilização da pessoa jurídica como palco para fraudes e abusos, sobretudo no descumprimento dos estatutos e da lei.

Requião revela na mesma oportunidade que a disregard doctrine (teoria da desconsideração) ainda teria possibilidade de adequar-se a qualquer sistema jurídico que adotasse o princípio da separação entre a pessoa jurídica e as pessoas físicas que a compõem, como norma de direito interno (FONSECA, 1996).

Diante de todo o processo histórico, compreende-se que as sociedades empresárias possuem direitos e obrigações distintas de seus sócios, constituindo uma individualização de sua autonomia. A pessoa jurídica, portanto, não se confunde com a pessoa dos seus sócios. No entanto, diante desta prerrogativa de ser um sujeito autônomo, a sociedade pode ser utilizada como instrumento para a concretização de fins ilícitos.

Motivada por esses fatores, floresceu a teoria da desconsideração da pessoa jurídica como meio de se evitar os abusos das manipulações no instituto da pessoa jurídica. Todavia, a personalidade jurídica só pode ser desconsiderada quando não se puder imputar diretamente o ato fraudulento ao sócio, pois a ação deste se envolve de ilicitude, um método de se contornar a lei. Não há o porquê de se desconsiderar a personalidade jurídica na ocasião em que o sócio possuir responsabilidade pela dívida da sociedade, quer pelo regime de responsabilidade da sociedade, quer por atos culposos em sua administração.

Fábio Ulhoa Coelho bem sintetiza bem a questão acerca das fraudes e manipulações do sócio ao dizer que haverá propósito fraudulento sempre que, encoberto pela "máscara" da pessoa jurídica, o sócio vise a prejudicar interesse de terceiros, em nome de anseios próprios (COELHO, 1999).

Desconsiderar a personalidade jurídica significa mitigar a autonomia inerente à pessoa jurídica. Com efeito, desconsiderada a autonomia patrimonial da pessoa jurídica, os seus sócios passam a responder pelas suas dívidas, observando-se que a desconsideração da personalidade jurídica não resulta na negativa definitiva da autonomia patrimonial da pessoa jurídica, mas no afastamento em relação à determinada obrigação (COELHO, 1999).

Sendo assim, ainda que díspares a pessoa dos sócios com a pessoa jurídica, em certas hipóteses haverá a autorização para se desconsiderar a distinção, visando que os patrimônios dos sócios respondam por obrigações da pessoa jurídica. Tal fenômeno se apresenta como uma exceção pelo fato de que a pessoa jurídica é dotada de personalidade jurídica, podendo exercer direitos e obrigações. Vigora no caso em questão o princípio da autonomia patrimonial entre pessoa jurídica e os sócios que a compõem.

Conclui-se que a teoria da desconsideração da personalidade jurídica tem como enfoque o de prevenir o uso inadequado da sociedade através de fraude ou abuso de direito que possam causar lesão aos credores. Tem-se a fraude, na ocasião onde o devedor realiza atos para dilapidar seu patrimônio, sendo insolvente ou na iminência de o ser. Quanto ao abuso de direito, este ocorre nos casos de excesso no uso do direito capaz de prejudicar terceiros.

No que concerne à corrente de João Casillo, a desconsideração não possui o objetivo de punição diretores e sócios ao responsabilizá-los pelas obrigações sociais. Isto pelo fato de que, pelo contrário, a própria entidade é que foi desviada de seus legítimos objetivos. Em assim sendo, a desconsideração poderia ser invocada em prol da sociedade, como no caso em que uma empresa componente de uma "holding", embora não tendo usado determinada marca no prazo de sua caducidade, não perde o direito de usá-la, por tê-lo feito outra empresa do mesmo grupo (FONSECA, 1996).

Lamartine Corrêa (CORRÊA, 1979), por sua vez, expõe o seguinte entendimento, in verbis:

“Os problemas ditos de 'desconsideração' envolvem frequentemente um problema de imputação. O que importa basicamente é a verificação da 


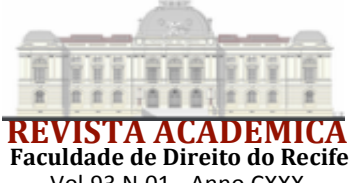

Vol.93 N.01 - Anno CXXX

resposta adequada à seguinte pergunta: no caso em exame, foi realmente a pessoa jurídica que agiu ou foi ela mero instrumento nas mãos de outras pessoas, físicas ou jurídicas? É exatamente porque nossa conclusão quanto a essência da pessoa jurídica se dirige a uma postura de realismo moderado, repudiamos os normativismos, os ficcionismos, os nominalismos, que essa pergunta tem sentido. Se é em verdade uma outra pessoa que está a agir, utilizando a pessoa jurídica como escudo, e se é essa utilização da pessoa jurídica, fora de sua função, que está tornando possível o resultado contrário à lei, ao contrato, ou às coordenadas axiológicas fundamentais da ordem jurídica (bons costumes, ordem pública), é necessário fazer com que a imputação se faça com predomínio da realidade sobre a aparência".

Por fim, imperioso mencionar que a exploração da atividade econômica pela via empresarial se resume na manifestação do legítimo direito de propriedade. Tanto que a jurisprudência alemã reconhece que o "direito ao exercício de uma exploração empresarial organizada" constitui objeto da garantia constitucional da propriedade (COMPARATO, 2000). Desta forma, a personalidade jurídica das sociedades é peça essencial para a iniciativa privada, impulsionando a atividade econômica e permitindo o pleno exercício do direito de propriedade. E isto ocorre porque o sistema de apropriação privada dos bens de produção se concentra na criação de empresas.

Em meio a essas constatações, é possível relacionar dois princípios presentes na Constituição Federal, a função social da propriedade (art. 5º, XXIII e art. 170, III) e a livre iniciativa (parágrafo único do art. 170, CF/88), surgindo o que Fredie Didier nomeia de "função social da pessoa jurídica empresária" (DIDIER, 2004). Este terceiro princípio nada mais é do que a fusão do direito máximo social com um dos maiores direitos individuais, dando às empresas uma importância dúplice: "a liberdade de empreender só será completa ao se satisfazer anseios sociais".

Assim, o instituto da desconsideração está de acordo com o princípio da função social da pessoa jurídica empresária, tanto por assegurar o interesse de terceiros (sociedade) lesados por ilicitudes no exercício da empresa, quanto por permitir que a livre iniciativa se mantenha ao restringir os casos de incidência (abuso ou desvio), evitando a insegurança jurídica.

\section{LEGISLAÇÕES E TEORIAS DA DESCONSIDERAÇÃO DA PERSONALIDADE JURÍDICA}

No âmbito legal, diversos diplomas legislativos incorporaram o espírito da teoria da desconsideração. A CLT em seu art.2 ${ }^{\circ}$, parágrafo segundo, por exemplo, prevê a responsabilidade solidária, para efeitos de relação empregatícia, da empresa principal e suas subordinadas quando constituírem um conglomerado econômico.

A razão legal é prevenção de situações onde o trabalho pudesse ser utilizado como meio de produção das várias empresas e o ônus de pagar a remuneração respectiva recaísse na empresa de patrimônio insuficiente, restando, em consequência, lesado o direito do empregado. Ressaltese que não se exige para tanto a prova de fraude ou de abuso de direito.

Fortifica-se, ainda, a aplicação da desconsideração devido à Lei das Sociedades por Ações (Lei 6.404/76), que estabelece limites ao reconhecimento da pessoa jurídica ao elidir a 


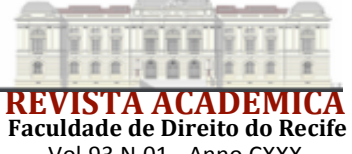

Vol.93 N.01-Anno CXXX

distinção entre essa e seus membros pelos atos ilícitos por eles praticados, bem como pelo que preza o Código de Defesa do Consumidor em seu caput e parágrafo $5^{\circ}$ do art. 28, que dispõem:

\begin{abstract}
"Art.28 - O Juiz poderá desconsiderar a personalidade jurídica da sociedade quando, em detrimento do consumidor, houve abuso de direito, excesso de poder infração da lei, fato ou ato ilícito ou violação dos estatutos ou contrato social. A desconsideração também será efetivada quando houver falência, estado de insolvência, encerramento ou inatividade da pessoa jurídica provocados por má administração.

(...)

$\S 5^{\circ}$ - Também poderá ser desconsiderada a pessoa jurídica sempre que sua personalidade for, de alguma forma, obstáculo ao ressarcimento de prejuízos causados aos consumidores."
\end{abstract}

Entretanto, é importante frisar que mesmo nos casos em que a responsabilidade do sócio for ilimitada e solidária, esta primeiramente deverá ser subsidiária, devendo ser executados os bens da sociedade de início e, somente na falta ou insuficiência dos mesmos, se executaria o patrimônio dos sócios que a compõem.

Ademais, a desconsideração da personalidade jurídica também é contemplada no artigo $4^{\circ}$ da Lei n. 9.605/1998 (Lei de infrações ambientais); no artigo 18, $\S 3^{\circ}$ da Lei n. 9.847/1999 (sistemas de distribuição de combustíveis); no artigo 34 da Lei 12.529/2011 (Sistema Brasileiro de Defesa da Concorrência); no artigo 14 da Lei 12.846/2013 (Lei anticorrupção); e no artigo 50 do Código Civil (BODART, 2019).

Dos vários dispositivos mencionados, praticamente todos possuem aplicações específicas da desconsideração. No entanto, a menção expressa no Código Civil representa a regra do Direito brasileiro, sendo aplicável sempre que não houver legislação especial.

Em sua redação original, o artigo 50 do Código Civil aponta a desconsideração nos seguintes termos:

\footnotetext{
“Art. 50. Em caso de abuso da personalidade jurídica, caracterizado pelo desvio de finalidade, ou pela confusão patrimonial, pode o juiz decidir, a requerimento da parte ou do Ministério Público quando lhe couber intervir no processo, que os efeitos de certas e determinadas relações de obrigações sejam estendidos aos bens particulares dos administradores ou sócios da pessoa jurídica."
}

De acordo com o disposto acima, o abuso da personalidade jurídica que motiva a desconsideração depende da ocorrência de desvio da finalidade ou de confusão patrimonial. $\mathrm{O}$ desvio de finalidade consistiria na prática de atos incompatíveis com o estatuto ou contrato social, configurando um abuso de direito.Contudo, há também quem adote uma concepção mais ampla, de modo que o desvio de finalidade seria "um uso anormal da pessoa jurídica que consiste no desvirtuamento da sua finalidade institucional" (BODART, 2019).

Vale ressaltar que tanto o desvio de finalidade, quanto o abuso da personalidade jurídica, poderão ser constatados com a comprovação da confusão patrimonial. Trata-se de modalidade objetiva de abuso da personalidade jurídica, situação em que "as fronteiras da autonomia patrimonial da sociedade e de seus sócios tornam-se fluidas" (BODART, 2019).

Não obstante, é pacífico o entendimento jurisprudencial do STJ de que não basta a mera ausência de patrimônio expropriável ou a dissolução para se decretar a desconsideração da personalidade jurídica (BODART, 2019). 
Quanto ao campo processual, o Código de Processo Civil de 2015 disciplinou a desconsideração da personalidade jurídica ao estabelecer um procedimento incidental como pressuposto para sua decretação. Deste modo, o CPC vigente dispõe (arts. 133 a 137) acerca dos sujeitos, efeitos e condições para que se alcance o patrimônio pessoal dos sócios.

Diante da variedade normativa apontada, surgem duas teses sobre a amplitude da responsabilidade dos sócios na hipótese de se desconsiderar a personalidade jurídica. Essas são denominadas de teoria maior e menor.

A primeira possui como regra desconsiderar a autonomia da sociedade nos casos em que for comprovado que seus sócios agiram com fraude ou abuso, ou ainda que existiu confusão patrimonial entre os bens da pessoa física e os bens da pessoa jurídica. O artigo 50 do Código Civil aborda a teoria maior da desconsideração. Geralmente, quando se trata na doutrina ou na jurisprudência de "desconsideração da personalidade jurídica", refere-se à teoria maior, por possuir ampla aplicabilidade (ASSIS, 2008).

Existe, nas pessoas jurídicas, o chamado pressuposto da licitude, o qual, de acordo com o disposto por Fábio Ulhoa Coelho, demonstra que "enquanto o ato é imputável à sociedade, ele é lícito. Torna-se ilícito apenas quando se o imputa ao sócio, ou administrador" (COELHO, 2005). Este pressuposto tem a função de diferir a desconsideração de outras hipóteses que não estão ligadas ao uso abusivo ou por meio de fraudes da pessoa jurídica, mas que também proporcionam a responsabilização dos sócios ou administradores da sociedade.

A teoria maior da desconsideração da personalidade jurídica possui duas ramificações, a objetiva e a subjetiva. Aquela se preocupa simplesmente com a confusão patrimonial, situação com maior facilidade probatória. Já a formulação subjetiva pressupõe a fraude e o abuso de direito, elementos de difícil margem de comprovação tendo em vista à necessidade de se provar a intenção do sócio em inadimplir seu débito. De qualquer forma, em ambas as ramificações não basta a insatisfação da obrigação para com os credores para se ensejar a desconsideração.

Tal entendimento está de acordo com a decisão do STJ, a qual firma a conclusão de que "a teoria maior não pode ser aplicada com a mera demonstração de estar a pessoa jurídica insolvente para o cumprimento de suas obrigações". Exige-se, aqui, para além da prova de insolvência, ou a demonstração de desvio de finalidade, ou a demonstração de confusão

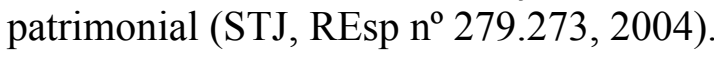

Seguindo para a segunda teoria da desconsideração da personalidade jurídica, a menor, esta se envolve de maior simplicidade, sendo suficiente o simples inadimplemento para com os credores, independente dos motivos que levaram a sociedade a deixar de se obrigar perante terceiros.

Aplica-se também a teoria menor nos casos de insolvência ou falência da pessoa jurídica, pouco importando se o sócio utilizou fraudulentamente o instituto ou se houve abuso de direito, tampouco se foi demonstrada a confusão patrimonial. $O$ que se faz essencial é a não frustração do credor da sociedade. Em havendo má administração, ou seja, mau uso do instituto, caberia a desconsideração conforme o artigo 28 da Lei n 8.078/1990, sendo acolhida então a teoria menor (ASSIS, 2008).

Diante do exposto, e seguindo a mesma jurisprudência apontada acima, o Superior Tribunal de Justiça firmou a seguinte conclusão:

"A teoria menor da desconsideração, por sua vez, parte de premissas distintas da teoria maior: para a incidência da desconsideração com base na teoria menor, basta a prova de insolvência da pessoa jurídica para o pagamento de suas obrigações, independentemente da existência de desvio de finalidade ou de confusão patrimonial”. 


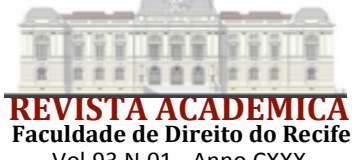

Vol.93 N.01 - Anno CXXX

Para esta teoria, o risco empresarial não pode ser suportado pelo terceiro que contratou com a pessoa jurídica, mas somente pelos sócios e/ou administradores desta, ainda que estes demonstrem conduta administrativa proba. Logo, haveria desconsideração mesmo que não exista prova sobre a conduta culposa ou dolosa dos sócios e/ou administradores da pessoa jurídica (STJ, REsp n⿳0 279.273, 2004).

Com base nisto, existe quem critique a aplicação da teoria menor, pois esta acarretaria em danos aos sócios ou administradores da sociedade, já que a intenção fraudulenta se tornaria descartável, importando apenas a existência de crédito do credor. Assim, haveria punição pelo simples inadimplemento, punindo da mesma forma uma sociedade com nítida intenção de causar dano e outra que não adimpliu seus créditos pelo risco da atividade, mas sem intuito ilegal.

De outro lado, existem jurisprudências que entendem que se a sociedade for insolvente, será possível a desconsideração de sua personalidade jurídica para solver o débito ante o credor, conforme se aponta a seguir:

"A tese levantada pelo recorrente, de que se deve aplicar a teoria da desconsideração da personalidade jurídica, não encontra guarida, uma vez que não se verifica nos autos a ocorrência dos seus requisitos basilares, tais como, a caracterização de fraude, a demonstração de insolvência ou, ainda, a latente confusão patrimonial existente entre a pessoa jurídica e a pessoa física do ora apelante" (STJ, Apelação Cível $n^{0}$ 2005.006802-1, 2005).

A aplicação da teoria menor, apesar das críticas, se enquadra no Direito do Consumidor, pois, independentemente se houve dolo ou culpa do agente causador do dano, este deve ser reparado. O mesmo aconteceria na esfera trabalhista, tendo em vista a hipossuficiência do operário, muitas vezes equiparada à do consumidor.

Como exemplo da adoção da teoria menor em uma relação de consumo, Nicole Vieira de Assis (ASSIS, 2019) relata a explosão do Osasco Plaza Shopping, ocorrida em 11 de junho de 1996 por conta de um vazamento de gás. Em síntese, não houve a intenção por parte dos sócios de causar danos. Todavia, em decorrência da explosão, cerca de 40 pessoas morreram, sem contar que mais de 300 foram feridas. Como o patrimônio da pessoa jurídica "shopping" era aquém ao montante das indenizações, sua personalidade jurídica foi desconsiderada com base na teoria menor, visando atingir o patrimônio pessoal dos sócios.

Este entendimento encontra-se previsto na lei, no $\S 5^{\circ}$ do artigo 28 , do Código de Defesa do Consumidor:

“\$ $5^{\circ}$ Também poderá ser desconsiderada a pessoa jurídica sempre que sua personalidade for, de alguma forma, obstáculo ao ressarcimento de prejuízos causados aos consumidores".

No campo trabalhista, como já mencionado, o presente entendimento se justifica em razão da hipossuficiência do trabalhador devido à sua subordinação, da dificuldade que apresenta em demonstrar a má-fé do administrador e do caráter alimentar e de subsistência do crédito trabalhista. Este também é o entendimento do E. Tribunal Regional do Trabalho da $15^{\text {a }}$ Região, que, em grau de recurso, expôs:

\begin{tabular}{lllllll} 
EXECUÇÃO. DESCONSIDERAÇÃO & DA & \multicolumn{2}{c}{ PERSONALIDADE } \\
JURÍDICA. DESNECESSIDADE DE PROVA & DE & DESVIO & DE \\
FINALIDADE, CONFUSÃO PATRIMONIAL & OU & ABUSO & DE
\end{tabular}




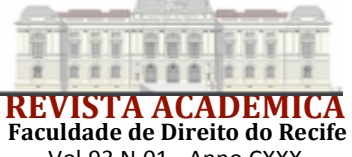

Vol. 93 N.01 - Anno CXXX

\begin{abstract}
DIREITO. Diante da proteção da pessoa humana, do valor social do trabalho, da hipossuficiência do trabalhador, do caráter alimentar do crédito e da dificuldade probatória de demonstrar a má-fé do administrador, no âmbito do Processo do Trabalho deve prevalecer a teoria objetiva da desconsideração da personalidade jurídica. Assim, para aplicação de tal instituto basta a falta de bens suficientes da empresa para quitação do débito trabalho (o que faz presumir a insolvência), independentemente de atos fraudulentos (TRT 15 Região - Campinas-SP, Ac. 57729/12-PATR, Proc. 014700-60.2009.5.15.0086 AP, DEJT 26/07/2012, pág. 670 , Rel. Eder Silvers, $11^{\text {a }}$ Câmara).
\end{abstract}

Tais circunstâncias peculiares em legislações especiais, somadas ao caráter dos direitos materiais tutelados, demonstram que a ótica em se analisar a desconsideração da personalidade jurídica no âmbito trabalhista/consumerista deve ser diferente à utilizada no procedimento comum, haja vista a diferença de equilíbrio na relação processual.

\title{
4 LEI DA LIBERDADE ECONÔMICA E CONSEQUÊNCIAS
}

Em meio às discussões sobre a desconsideração da personalidade jurídica, foi aprovada a Lei n. 13.874/19, com o fim de se estabelecer "normas de proteção à livre iniciativa e ao livre exercício de atividade econômica" e dispor "sobre a atuação do Estado como agente normativo e regulador, nos termos do disposto no inciso IV do caput do art. $1^{\circ}$, no parágrafo único do art. 170 e no caput do art. 174 da Constituição Federal" (art. $1^{\circ}$ da Lei da Liberdade Econômica).

Apesar do pequeno número de artigos (sete, contando as disposições finais), a Lei da Liberdade Econômica alterou alguns dispositivos importantes no Código Civil, como o artigo 980-A (ao se inserir o $\S 7^{\circ}$ para se destacar a autonomia entre os patrimônios do instituidor e da EIRELI) e o artigo 1052 (ao se instituir a possibilidade de uma sociedade limitada unipessoal).

No mesmo contexto, o art. 50 do Código Civil também sofreu alterações, de modo que o instituto da desconsideração da personalidade da pessoa jurídica recebeu algumas peculiaridades. Antes da Lei n. 13.874/19, a norma assim estava redigida:

“Art. 50. Em caso de abuso da personalidade jurídica, caracterizado pelo desvio de finalidade, ou pela confusão patrimonial, pode o juiz decidir, a requerimento da parte, ou do Ministério Público quando lhe couber intervir no processo, que os efeitos de certas e determinadas relações de obrigações sejam estendidos aos bens particulares dos administradores ou sócios da pessoa jurídica”.

Contudo, com a edição da Lei da Liberdade Econômica, as alterações buscaram conceituar os requisitos da desconsideração da personalidade jurídica, quais sejam, o "abuso de personalidade", "desvio de finalidade" e "confusão patrimonial":

“Art. 50. Em caso de abuso da personalidade jurídica, caracterizado pelo desvio de finalidade ou pela confusão patrimonial, pode o juiz, a requerimento da parte, ou do Ministério Público quando lhe couber intervir no processo, desconsiderá-la para que os efeitos de certas e determinadas relações de obrigações sejam estendidos aos bens particulares de administradores ou de sócios da pessoa jurídica beneficiados direta ou indiretamente pelo abuso. 
$\S 1^{\circ}$ Para fins do disposto neste artigo, desvio de finalidade é a utilização dolosa da pessoa jurídica com o propósito de lesar credores e para a prática de atos ilícitos de qualquer natureza.

$\S 2^{\circ}$ Entende-se por confusão patrimonial a ausência de separação de fato entre os patrimônios, caracterizada por:

I - cumprimento repetitivo pela sociedade de obrigações do sócio ou do administrador ou vice-versa;

II - transferência de ativos ou de passivos sem efetivas contraprestações, exceto o de valor proporcionalmente insignificante; e

III - outros atos de descumprimento da autonomia patrimonial.

$\S 3^{\circ} \mathrm{O}$ disposto no capute nos $\S 1^{\circ}$ e $\S 2^{\circ}$ também se aplica à extensão das obrigações de sócios ou de administradores à pessoa jurídica.

$\S 4^{\circ}$ A mera existência de grupo econômico sem a presença dos requisitos de que trata o caputnão autoriza a desconsideração da personalidade da pessoa jurídica.

$\S 5^{\circ}$ Não constitui desvio de finalidade a mera expansão ou a alteração da finalidade original da atividade econômica específica da pessoa jurídica".

Motivados pela inovação jurídica do art. 50 do Código Civil, algumas discussões se iniciaram em pontos específicos. Dentre elas, destacam-se: a nova conceituação do desvio de finalidade e da confusão patrimonial; a amplitude de responsabilização dos sócios; e a aplicação dessa nova ótica em leis especiais, como a trabalhista e do consumidor.

\subsection{DESVIO DE FINALIDADE}

A primeira das polêmicas a ser analisada está presente no $\S 1^{\circ}$ do artigo 50 do Código Civil. Nesta parte, há a definição de desvio de finalidade, sendo este um ato doloso da pessoa jurídica com a intenção de lesar credores e para praticar ilícitos de qualquer natureza.

Nota-se que a intenção primordial dessa disposição é a de evidenciar a necessidade do elemento subjetivo "dolo" para que se caracterize o desvio. Sendo assim, o artigo 50 do Código Civil mantém a defesa da teoria maior da desconsideração, mas acrescenta outro requisito para sua configuração.

A despeito das críticas sobre a exigência de "dolo" na configuração de desvio de finalidade, tais como a apontada por Pablo Stolze (STOLZE, 2019), ressalta-se que, na prática, existiu apenas a separação entre suposição e materialidade. Isto não só pelo fato de que um ilícito pressupõe elemento subjetivo, mas também por se evitar que se enquadre na mesma situação um caso em que as provas indicam o dolo com um em que não há comprovação suficiente.

Por esses motivos, a alteração legislativa está em conformidade com os entendimentos da Corte Superior, que já afirmou serem considerados em desvio de finalidade os atos dos sócios 
com intenção de lesar terceiros com a ocultação de bens de pessoas físicas no patrimônio de pessoas jurídicas (BODART, 2019).

Obviamente, o elemento subjetivo no desvio de finalidade só será configurado de justiça em situações em que a relação jurídica não aponta hipossuficiência contra a empresa. Assim, da mesma forma que se aplica o in dubio pro misero no Direito do Trabalho e do Consumidor, nas relações civis entre contratantes com mesma capacidade (logo, entre empresários, ou entre empresário e investidor), bem como nas relações tributárias, vigeria o princípio do in dubio pro libertatem, sob pena de aniquilar-se a autonomia patrimonial da pessoa jurídica por completo (princípio este presente no art. $3^{\circ}$, inciso V, da Lei da Liberdade Econômica).

Contudo, não se pode ignorar a possibilidade da própria norma motivar confusões, prejudicando o desenvolvimento da economia. Tanto que Marcelo Lauar Leite (LEITE, 2019) é incisivo ao dispor sobre a MP que se converteu na Lei n. 13.874/19:

\begin{abstract}
"Quanto menos seguro o investidor se sentir quanto à abrangência de sua responsabilidade ao aportar capital em uma sociedade empresária, mais atrativo será emprestar seu capital ao Tesouro Nacional ou a instituições financeiras. Se é certo que 'o valor maior de toda ciência consiste em dizer-nos quais seriam as consequências caso as condições se tornassem diferentes do que são', o parlamento e a presidência da República precisam estar atentos à autossabotagem constante da MP. Não há desburocratização, inovação e liberalização que resistam ao indisfarçável risco jurídico da alteração da regra-base de desconsideração da personalidade jurídica”.
\end{abstract}

Para se evitar a insegurança nos investimentos será necessário o debate doutrinário e jurisprudencial acerca das situações em que o dolo estaria evidentemente configurado, excluindo a configuração de desvio de finalidade nos demais casos. Portanto, será através de uma interpretação restrita que se elencará situações de ato evidentemente doloso, sendo as demais situações (e nas relações já mencionadas) pautadas pelo in dubio prolibertatem.

Por fim, importante ressaltar outra condição imposta pela Lei da Liberdade Econômica, mais precisamente em seu $\S 5^{\circ}$. Em tal parágrafo, há a exclusão de duas hipóteses que não serão suficientes para motivar a desconsideração, quais sejam: a mera expansão ou a alteração da finalidade original da atividade econômica específica da pessoa jurídica.

Estas exceções, sob a ótica que motivou a Lei da Liberdade Econômica, seriam situações que por si só não configurariam desvio, apesar da possibilidade de se tornarem indícios.

De um lado, nota-se que a mera expansão é bem diferente de se alterar toda a finalidade original da empresa. Até porque existe mais probabilidade de fraudes ao se mudar todo o objetivo empresarial. Também seria possível alegar que uma mudança brusca na finalidade da empresa entraria em contradição com a livre iniciativa por se configurar um abuso ao próprio princípio, restando caracterizado um mau uso de tal liberdade (abuso de direito).

No entanto, não se pode punir o direito à livre iniciativa por presunções de fraudes, tendo em vista a importância social e econômica dos empreendimentos. Será necessário, portanto, que a jurisprudência estabeleça interpretações razoáveis para que o instituto da desconsideração não se torne ineficaz, mas que também não se torne um óbice à atividade econômica.

\title{
4.2 CONFUSÃO PATRIMONIAL
}

Configurando o segundo objeto de discussões, a conceituação de confusão patrimonial recebeu modificações com a Lei da Liberdade Econômica. De acordo com o teor do $\S 2^{\circ}$ do artigo 50 do Código Civil, a confusão patrimonial se caracteriza pela ausência na separação de 


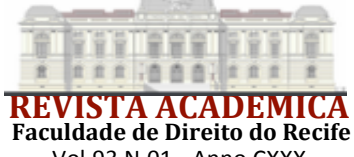

Vol.93 N.01 - Anno CXXX

fato entre os patrimônios da pessoa física e jurídica. Com base nisto, os patrimônios devem ter ligação apenas à pessoa física ou jurídica, situação em que a impossibilidade de separação acarretaria na confusão patrimonial.

Ciente das dificuldades em se prever as situações em que os patrimônios entre pessoas distintas se confundem, o mesmo parágrafo dispôs condições de incidência.

Em seu primeiro inciso, há o requisito de que a personalidade jurídica seja utilizada como instrumento para que seu controlador cumpra suas obrigações ou vice-versa. Deve existir, portanto, uma assunção de obrigação de uma pessoa sobre a outra somada com a ausência na separação de fato dos patrimônios.

Quanto ao inciso II, este prevê a necessidade de "transferência de ativos ou de passivos sem efetivas contraprestações, exceto o de valor proporcionalmente insignificante". Deste modo, a transferência de ativos ou de passivos sem a devida justificativa econômica configura a utilização do patrimônio da pessoa jurídica pelos sócios ou administradores e vice-versa. Tal situação pode ser identificada quando, por exemplo, o sócio "adquire" bens da pessoa jurídica sem repassar para esta os valores correspondentes, ou no caso de empréstimos entre a pessoa jurídica e o sócio.

Por derradeiro, o inciso III do $\S 2^{\circ}$ já mencionado, indica a existência de um rol meramente explicativo, elencando quaisquer outros atos que não observem a autonomia patrimonial entre pessoa jurídica e seus constituintes. Como bem explicita Pablo Stolze (STOLZE, 2019):

\begin{abstract}
"Podem traduzir confusão patrimonial, por exemplo, a movimentação bancária em conta individual do sócio para as operações habituais da sociedade, o lançamento direto como despesa da pessoa jurídica de gastos pessoais do sócio ou administrador etc".
\end{abstract}

Ao contrário dos debates sobre o desvio de finalidade, a confusão patrimonial recebeu mais detalhes normativos, de modo que seja pelos primeiros dois incisos, seja pela confirmação de um rol exemplificativo, será possível garantir a segurança jurídica e dos investimentos sem maiores trabalhos da doutrina e jurisprudência. De qualquer forma, ressalte-se que as disposições sobre a confusão patrimonial, ao serem aplicadas, devem observar os preceitos e normas basilares de cada ramo do Direito.

\title{
4.3 EXTENSÃO DA RESPONSABILIDADE
}

O terceiro ponto da Lei da Liberdade Econômica que merece análise está na abrangência da responsabilidade na incidência de abuso da personalidade jurídica. Antes das modificações no Código Civil, havia dúvidas se a desconsideração da pessoa jurídica poderia se estender aos sócios ou administradores de maneira irrestrita, ainda que determinado sócio fosse minoritário (no caso das sociedades anônimas).

Por outro lado, e ao aplicar a teoria maior da desconsideração no âmbito civil, o Superior Tribunal de Justiça entendia que todos aqueles que se beneficiam do abuso da personalidade jurídica ou, que ao menos contribuam para tanto, deveriam ser responsabilizados. Tanto que afirmava que os "os efeitos da desconsideração da personalidade jurídica somente alcançam os sócios participantes da conduta ilícita ou que dela se beneficiaram, ainda que se trate de sócio majoritário ou controlador" (STJ, REsp 1325663, 2012).

Seguindo o mesmo raciocínio da Corte Superior, a modificação do caput do art. 50 do Código Civil trazida pela Lei n. 13.874/2019 indica de forma expressa que a desconsideração servirá apenas para atingir quem se beneficiou direta ou indiretamente pelo abuso. Tecendo elogios sobre essa alteração, Pablo Stolze (STOLZE, 2019) revela que: 


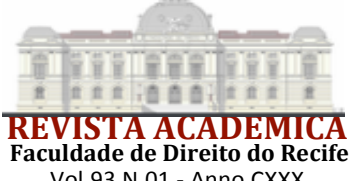

Faculdade de Direito do Reci

Vol.93 N.01 - Anno CXXX

\begin{abstract}
"Andou muito bem o novo diploma ao acrescentar, no final do artigo 50, a expressão 'beneficiados direta ou indiretamente pelo abuso', porquanto a desconsideração é instrumento de imputação de responsabilidade, não podendo, por certo, sob pena de se ignorar a exigência do próprio nexo causal, atingir sócio que não experimentou nenhum benefício (direito ou indireto) em decorrência do ato abusivo perpetrado por outrem".
\end{abstract}

Deste modo, a exigência de benefício direto ou indireto se apoia de forma harmônica ao conceito de responsabilidade do Código Civil (art. 927 do C.C.), tendo em vista que os beneficiários do ato ilícito possuem obrigação de indenizar por colaborarem ou se omitirem de minimizarem o dano. Em mesmo sentido, aquele sócio que não se beneficiou de nenhuma forma não deverá responder por ato abusivo externo à sua esfera obrigacional.

Ainda no campo da responsabilidade, o parágrafo quarto do artigo 50 do Código Civil resolveu dispor sobre a desconsideração em grupos econômicos. Aliado ao entendimento jurisprudencial (STJ, AgRg no AREsp 549.850/RS) de que a integração em grupo econômico não é suficiente para ensejar a desconsideração, o mencionado parágrafo revela que a "mera existência de grupo econômico sem a presença dos requisitos de que trata o caput não autoriza a desconsideração da personalidade da pessoa jurídica".

Diante dessa disposição, o desvio de finalidade ou a confusão patrimonial serão pressupostos para se desconsiderar a personalidade jurídica de sociedades que integrem grupo econômico, sem se esquecer, é claro, de que só serão atingidas aquelas que se beneficiarem direta ou indiretamente do abuso da personalidade jurídica.

Todavia, as interpretações nos casos concretos devem se revestir de cautela quando se tratar do benefício indireto. Afinal, o simples fato de integrar o mesmo grupo não deve se caracterizar como benefício indireto, sob pena de se ferir a autonomia jurídica das integrantes do grupo (STOLZE, 2019).

\title{
4.4 APLICAÇÃO EM LEIS ESPECIAIS E NO DIREITO CIVIL/COMERCIAL
}

Constituindo o último dos principais pontos polêmicos da Lei da Liberdade Econômica, a possibilidade de aplicação do art. 50 do Código Civil nas relações civis e especiais (trabalhista e consumerista) não deve seguir as mesmas interpretações, gerando uma segmentação devido a dois pontos específicos.

De início, e como já mencionado, deve-se ter em mente que as relações comerciais e tributárias não possuem uma hipossuficiência em detrimento da empresa, situação que se deve aplicar o in dubio pro libertatem em obediência aos princípios da livre iniciativa e função social da pessoa jurídica. Por outro lado, existindo um crédito trabalhista, de caráter alimentar, bem como na incidência de uma relação de consumo, a presunção se estabelece contra a empresa pela hipossuficiência do trabalhador/consumidor.

Além disso, as legislações especiais trabalhista e consumerista adotam a teoria menor da desconsideração, a qual possui como único requisito a inadimplência da pessoa jurídica. Por óbvio, a vigência do Código de Processo Civil de 2015 instituiu o incidente para se desconsiderar a personalidade jurídica.

Ainda assim, requisitos contrários aos princípios da seara trabalhista como a presença do elemento subjetivo (dolo) não devem ser aplicados pela falta da compatibilidade exigida no art. 15 do CPC e art. 769 da CLT.

$\mathrm{Na}$ análise de tais dispositivos, inclusive, nota-se que o art. 15 do Novo CPC estipula que suas normas serão aplicadas no processo trabalhista, eleitoral e administrativo no caso de omissão (subsidiariamente) e na existência de compatibilidade (supletivamente). Quanto ao art. 769 da CLT, este prevê que as normas do Código de Processo Civil serão aplicadas no campo 


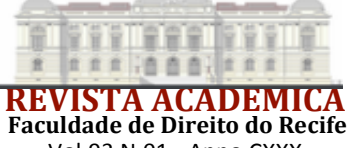

Voculdade de Direito do Recife

Vol.93 N.01 - Anno CXXX

trabalhista nos casos omissos, exceto o que for incompatível com preceitos e normas do Direito do Trabalho.

Até porque, como exposto nos tópicos acima, as alterações sobre a desconsideração da personalidade jurídica ocorreram em diploma civil, o qual adota a teoria maior. Desta forma, apenas essa teoria recebeu alterações, de modo que as legislações especiais (que adotam a teoria menor) não seriam afetadas no que ferirem seus preceitos basilares.

Entretanto, na hipótese de se assumir a aplicação do artigo 50 do Código Civil nas relações especiais, dois caminhos se apresentam pertinentes. O primeiro está na possibilidade da doutrina e da jurisprudência elencarem de maneira justa algumas situações em que o dolo no desvio de finalidade fosse presumido, colaborando com os princípios da eficiência e celeridade da justiça. Em suma, seria o caso de se estipular condutas que por si só contivessem o dolo inserido (intrínseco), seja ele genérico ou eventual.

Não menos importante será a hipótese de se inverter o ônus da prova (art. $373, \S 1^{\circ}, \mathrm{CPC}$ ) nos campos trabalhistas e do consumidor, situação em que caberia à empresa comprovar a não existência de dolo (no desvio), a falta de requisitos para a confusão patrimonial ou a inexistência de benefício direto ou indireto. Tal inversão poderia ocorrer tanto no decorrer do processo em si, quanto na existência do incidente de desconsideração da personalidade jurídica, mas sempre, é claro, fornecendo a oportunidade da parte se desincumbir do ônus.

\section{CONCLUSÃO}

A Lei n. 13.874/19 tem a capacidade de promover o desenvolvimento da economia brasileira e a diminuição do desemprego. Suas disposições sobre o instituto da desconsideração da personalidade jurídica, em específico, buscam resguardar tanto a autonomia privada e a livre iniciativa, quanto os interesses sociais referentes à atividade econômica. A Lei, portanto, está em harmonia com o princípio da função social da pessoa jurídica.

Por meio de uma concepção positiva, o novo artigo 50 do Código Civil adiciona conceitos e elementos relevantes para a teoria maior da desconsideração. O elemento subjetivo passa a ter relevância no desvio de finalidade, criando uma separação entre fraudes reais e meras suposições que não se comprovam de fato. Além disso, o mesmo artigo dispõe de requisitos para a confusão patrimonial, bem como expande a responsabilidade para qualquer espécie de benefício sobre o abuso da personalidade jurídica.

De certo, alguns pontos de conceituação merecem o foco da doutrina e jurisprudência, de forma a harmonizar as disposições da Lei da Liberdade Econômica com o Direito. Exemplos de casos concretos para enquadramento na desconsideração podem impedir a queda de investimentos motivada pelas incertezas da responsabilização e da configuração de abuso.

Assim, seria possível equilibrar os direitos de credores com o in dubio pro libertatem nas relações comerciais e tributárias, bem como separar os casos com evidente ilegalidade das situações que ensejariam interpretação desfavorável à empresa pelo mero indício probatório.

Do outro lado, constituindo uma concepção negativa, ressalta-se a incompatibilidade das alterações da Lei n. 13.874/19 com as normas especiais como a trabalhista e do consumidor pelo fato destas já possuírem sua própria relação de hipossuficiência e por adotarem a teoria menor da desconsideração.

Ademais, ainda que se entenda que a aplicação do artigo 50 do Código Civil não fere os preceitos basilares das legislações especiais, destaca-se que o melhor caminho para sua aplicação será tanto por meio da elaboração de situações em que o dolo se presume na própria conduta, quanto na hipótese de se inverter o ônus probatório para os integrantes da pessoa jurídica.

Evidente que nenhuma norma possui o status de perfeição. No entanto, a nova ótica de se tratar os empreendimentos nas relações comerciais e tributárias pode ser um dos passos primordiais para que o Brasil retorne aos bons índices de emprego e desenvolvimento. Afinal, 
não só a população em si sofre com quem abusa da personalidade jurídica, mas também aqueles que buscam sobreviver honestamente por meio da atividade econômica.

\section{REFERÊNCIAS}

ASSIS, Nicole Vieira de. As teorias e os pressupostos de aplicação da desconsideração da personalidade jurídica no direito brasileiro. Âmbito Jurídico. 2008.

BODART, Bruno et al. MP 881 e a desconsideração da personalidade jurídica no Código Civil. 2019. Disponível em: https://www.jota.info/opiniao-e-analise/colunas/pensandodireito/mp-881-e-a-desconsideracao-da-personalidade-juridica-no-codigo-civil23052019\#sdfootnote25sym . Acesso em: 21/04/2021

COELHO, Fábio Ulhoa. Curso de Direito Comercial. São Paulo: Saraiva, v. 2, 1999.

COELHO, Fábio Ulhoa. Curso de direito comercial, volume 2. $8^{\mathrm{a}}$ edição. São Paulo: Saraiva, 2005.

COMPARATO, Fábio Konder. Direitos e deveres fundamentais em matéria de propriedade. In:STROZAKE ,Juvelino José (org.). A questão agrária e a justiça. São Paulo: RT, 2000.

CORRÊA, Lamartine. A dupla crise da pessoa jurídica. Saraiva. São Paulo. 1979.

DIDIER JR. Fredie. Aspectos processuais da desconsideração da personalidade jurídica. São Paulo: Saraiva, 2004.

FONSECA, Suiane de Castro. Teoria da desconsideração da personalidade jurídica. 1996. Monografia (Graduação em Direito) - Universidade Federal do Rio Grande do Norte, Natal, 1996.

LEITE, Marcelo Lauar. Autossabotagem na MP da "liberdade econômica". 2019. Disponível em: $\quad$ https://www.migalhas.com.br/dePeso/16,MI302115,71043Autossabotagem + na $+\mathrm{MP}+\mathrm{da}+$ liberdade+economica. Acesso em: 21/04/2021

STOLZE, Pablo. A Medida Provisória da Liberdade Econômica e a desconsideração da personalidade jurídica (art. 50, CC). 2019. Disponível em: https://jus.com.br/artigos/73648/amedida-provisoria-da-liberdade-economica-e-a-desconsideracao-da-personalidade-juridica-art50-cc. Acesso em: 21/04/2021 